Review

\title{
Femtosecond Laser Filamentation for Atmospheric Sensing
}

\section{Huai Liang $\mathrm{Xu}{ }^{1, *}$ and See Leang $\mathrm{Chin}^{2}$}

1 Key Laboratory on Integrated Optoelectronics, College of Electronic Science and Engineering, Jilin University, 2699 Qianjin Street, Changchun, 130012, China

2 Department of Physics, Engineering Physics and Optics \& Center for Optics, Photonics and Laser (COPL), Université Laval, Québec City, QC, G1V0A6, Canada;

E-Mail: See.Leang.Chin@copl.ulaval.ca

* Author to whom correspondence should be addressed; E-Mail: huailiang@jlu.edu.cn; Tel.: +86-431-8516-8244, ext. 8208; Fax: +86-431-8516-8281.

Received: 19 November 2010; in revised form: 10 December 2010 / Accepted: 13 December 2010 / Published: 23 December 2010

\begin{abstract}
Powerful femtosecond laser pulses propagating in transparent materials result in the formation of self-guided structures called filaments. Such filamentation in air can be controlled to occur at a distance as far as a few kilometers, making it ideally suited for remote sensing of pollutants in the atmosphere. On the one hand, the high intensity inside the filaments can induce the fragmentation of all matters in the path of filaments, resulting in the emission of characteristic fluorescence spectra (fingerprints) from the excited fragments, which can be used for the identification of various substances including chemical and biological species. On the other hand, along with the femtosecond laser filamentation, white-light supercontinuum emission in the infrared to UV range is generated, which can be used as an ideal light source for absorption Lidar. In this paper, we present an overview of recent progress concerning remote sensing of the atmosphere using femtosecond laser filamentation.
\end{abstract}

Keywords: femtosecond laser; filamentation; remote sensing

\section{Introduction}

Laser-based spectroscopic techniques, such as differential absorption light detection and ranging (DIAL), tunable diode laser absorption spectroscopy and laser-induced fluorescence, have been 
extensively employed for sensing atmospheric trace species because of their high sensitivity, non-intrusiveness and real-time analysis [1-3]. However, conventional laser remote sensing techniques usually require coherent sources with a particular wavelength depending on the species to be sensed, that is, the laser may only be optimized for one pollutant at a time. For example, in the DIAL technique (see, e.g., [1]), the laser light has to be alternatively switched to an on-resonance wavelength, where the species under investigation absorbs, and to a neighboring off-resonance wavelength, where the species does not absorb. Although this technique has been extensively used to measure the pollutants like $\mathrm{NO}, \mathrm{SO}_{2}, \mathrm{O}_{3}, \mathrm{Hg}, \mathrm{CH}_{4}$, and benzene with sensitivities in the ppb-range, the laser wavelengths required are over wide spectral ranges, which are not achievable with only one laser source. In particular, for biological agent detection, the UV laser-induced fluorescence Lidar technique is usually used, where broadband spectra are generated. However, such broad band fluorescence represents a weakness insofar as efficient and effective identification of bio-molecules is concerned.

On the other hand, nanosecond laser-induced breakdown spectroscopy (LIBS) is a powerful technique for rapid, on-line and multi-elemental material analysis with only one laser source (see e.g., [4]). It has also been suggested as a potential technique for identifying biological agents $[5,6]$. This technique is based on the emission spectroscopy of materials ablated into a small plasma by a tightly focused laser beam, generally a Q-switched Nd:YAG laser. However, a key aspect of remote LIBS is to ensure that sufficiently high laser intensities are achieved at a remote position to induce a plasma breakdown on the sample. Clearly, because of diffraction, the proportionality of the focal diameter to the distance leads to the difficulty in delivering high laser intensities over long distances, which limits the operation range of conventional nano-LIBS.

Recent advances in high-power femtosecond laser technologies have made it possible to use only one laser source for simultaneously sensing of multi-pollutants. High peak powers of femtosecond laser pulses with pulse widths of less than 50 fs are commercially available and can be made to be relatively compact. When powerful femtosecond laser pulses propagate in air, filaments appear as a result of the dynamic balance between Kerr self-focusing and defocusing by both the plasma produced by multiphoton/tunnel ionization of the air molecules [7-12]. The equilibrium limits the laser intensity inside the filament core to about $5 \times 10^{13} \mathrm{~W} / \mathrm{cm}^{2}$ (intensity clamping) [13-15]. This peak intensity inside the filament is high enough to dissociate/ionize other gas molecules [16,17], generate higher harmonics [18-21], induce other parametric processes [22] as well as THz radiation [23-27], and explode dust particles and aerosols or induce partial breakdown on solid targets [28,29]. In addition, the non-linear propagation of powerful femtosecond pulses can also lead to the white-light emission with an extraordinary broad spectral content ranging from IR to UV [30-37]. In particular, it is worth stressing that filamentation can even be formed at a far distance in an adverse atmospheric environment [38], and hardly disturbed by turbulence [39-41]. Moreover, the filamentation of powerful femtosecond pulses can be controlled to occur at a distance as far as a few kilometers in the atmosphere [42]. Such properties of the filaments make them a promising technique with high potential in view of applications in remote sensing of trace chemical and biological agents and pollutants in the atmosphere $[10,43]$.

In this paper, we will mainly present two filamentation-based schemes proposed for remote sensing of multi-pollutants. One of the schemes is to utilize the ultra-broad spectral content of the self-transformed white-light laser pulses during laser filamentation [7,44]. In air this white light laser, 
popularly called supercontinuum, provides an ideal light source for absorption Lidar [45]. The second one is to utilize the high intensity inside the filament $\left(5 \times 10^{13} \mathrm{~W} / \mathrm{cm}^{2}\right)$. Such peak intensity in the filament is high enough to dissociate/ionize gas molecules, to explode fine particles (dusts and aerosols), and to induce a so-called breakdown on solid targets, resulting in the emission of characteristic fluorescence spectra (fingerprints) from the excited fragments, atom or ions. The fluorescence emissions are 'clean' and practically free of plasma continuum. It is a universal strong-field phenomenon inside the filament for all targets ranging from gases, aerosols to solids $[17,46,47]$, and thus can be used for identifying various substances including chemical and biological species in the atmosphere [48].

The present article is organized as follows. In Section 2, we will briefly present the physics responsible for the formation and termination of filamentation in air. This is followed in Section 3 by an overview of recent progress concerning remote sensing of atmosphere using filament-induced fluorescence technique. In Section 4, the analysis of multi-parameter atmosphere by using filamentation induced white-light continuum is briefly reviewed. Finally, the summary and conclusions are presented in Section 5.

\section{Formation and Termination of Femtosecond Laser Filamentation in Air}

The basic physical mechanisms of femtosecond laser filamentation in transparent media are now basically understood (see e.g., the review papers [7-12] and references therein). The propagation of femtosecond laser pulses in air is dominated by the dynamical balance between the Kerr effect which focuses the beam and creates a plasma and the de-focusing of laser pulses by the plasma. This equilibrium leads to the formation of self-guided stable channels of plasma with diameters of 100-200 $\mu \mathrm{m}$ called filaments. It was shown that self-focusing occurs only when the input laser power, $P_{\text {in }}$, exceeds a critical threshold (critical power), $P_{c}$, where $P_{c}=3.72 \lambda^{2} / 8 \pi n_{0} n_{2}$ with $n_{0}$ and $n_{2}$ the linear index of refraction and second order nonlinear index coefficient, respectively [49]. In air, the critical power for self-focusing was recently measured to be about $10 \mathrm{GW}$ for a $42 \mathrm{fs}$ laser pulse, and it gradually decreases to about $5 \mathrm{GW}$ for a chirped pulse with duration longer than $200 \mathrm{fs}$ [50]. However, it was also found that in some cases the filamentation would be terminated even if the laser power is higher than the critical power due to the diffraction of laser pulses by the plasma produced in the filamentation process, which indicates that the remaining self-focusing power could not overcome the divergence of the laser beam [51].

Furthermore, it was demonstrated that the low intensity background energy (energy reservoir) surrounding filaments plays an important role in their formation [52-55]. When particles like water droplets, snow crystals and dusts with dimensions comparable to or larger than the filament diameters block the filament in the propagation path of laser pulses, the energy in the reservoir will refill the hot core (replenishment) [52,56-58]. Such filamentation properties clarify why filaments can be formed and propagate under adverse atmospheric conditions such as rain, compared to the linear propagation of the beam. The effect of energy reservoir on the formation of filaments was also observed by examining whether the filament would be terminated or not after blocking the background energy [59,60]. It was found that the background can contain up to $90 \%$ of the pulse energy, which is benefitial for maintaining the filament formation [61], and thus the filamentation process could be 
terminated immediately after the energy reservoir was blocked [62]. As a consequence, for the filament formation it is more critical to avoid a diffraction of energy at the edges of the background than a collision with a (small) droplet near the center.

\section{Femtosecond Filament-Induced Fluorescence Technique}

\subsection{Clean Fluorescence}

The fluorescence emission from the plasma-filament was first shown for nitrogen molecules in air, and it was found that the fluorescence spectra were very clear and free of plasma continuum [16], as shown in Figure 1, in which a 200 ps long (upper) and 42 fs short (bottom) laser pulse was focused in air.

Figure 1. Long pulse-induced breakdown and short pulse filament-induced fluorescence spectra of air obtained in the ambient atmosphere. For both cases, the energy per pulse was $5 \mathrm{~mJ}$. The durations of the short and long laser pulses were $42 \mathrm{fs}$ and $200 \mathrm{ps}$, respectively. The short and long laser pulses were focused into air respectively by lens with a focal length of $\mathrm{f}=100 \mathrm{~cm}$ and $\mathrm{f}=5 \mathrm{~cm}$. The lines superposed on the continuum shown in the upper spectrum mainly come from the emissions of singly charged nitrogen and oxygen atoms, while the spectral bands shown in the bottom spectrum result from neutral and ionic molecular nitrogen.

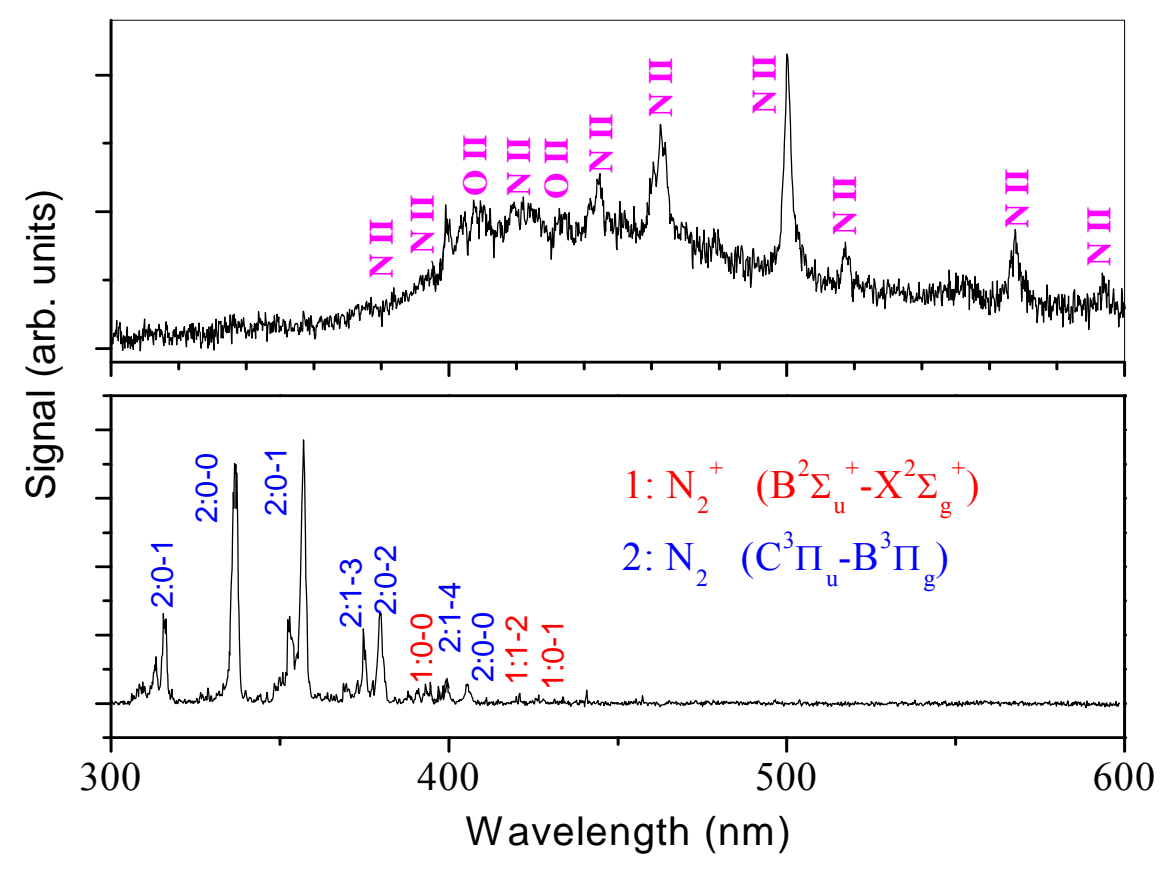

The clean filament-induced fluorescence spectrum in air may originate from the fact that free electrons induced by the short laser pulse in the plasma filament do not have enough time to absorb more energy from laser photons through inverse Bremsstrahlung [63], and that the plasma density $\left(\sim 10^{14}-10^{16} \mathrm{~cm}^{-3}\right)$ and temperature $(\sim 5,800 \mathrm{~K})$ are very low in the filament plasma $[64,65]$. This also leads to a simple recombination picture of electrons and ions in the plasma filament for the emission of the second positive band system $\left(\mathrm{C}^{3} \Pi_{\mathrm{u}}-\mathrm{B}^{3} \Pi_{\mathrm{g}}\right.$ transition) of $\mathrm{N}_{2}$, which was ascribed to the primary 
reaction $\mathrm{N}_{2}{ }^{+}+\mathrm{N}_{2} \rightarrow \mathrm{N}_{4}{ }^{+}$followed by the recombination with the electron $\left(\mathrm{N}_{4}{ }^{+}+\mathrm{e} \rightarrow \mathrm{N}_{2}{ }^{*}+\mathrm{N}_{2}\right)$ resulting in the excitation of the neutral excited state $\mathrm{N}_{2} *\left(\mathrm{C}^{3} \Pi_{\mathrm{u}}\right)$ [65]. While the fluorescence emission from the first negative band system $\left(\mathrm{B}^{2} \Sigma_{\mathrm{u}}^{+}-\mathrm{X}^{2} \Sigma_{\mathrm{g}}{ }^{+}\right.$transition) of $\mathrm{N}_{2}^{+}$was theoretically ascribed to intense laser-induced multiphoton or tunnel ionization of inner-valence electrons of neutral nitrogen molecules, leaving the molecular ion $\mathrm{N}_{2}^{+}$in the excited state $\mathrm{B}^{2} \Sigma_{\mathrm{u}}^{+}$[66]. Filament-induced clean fluorescence emission from the solid target was also observed, as shown in Figure 2, in which the lead spectrum was recorded in the region of 200-700 nm with the laser pulses focused in air using a fused silica lens $(\mathrm{f}=5 \mathrm{~m})$. The lead sample was fixed on a rotating stage to provide new, unprocessed material for successive laser shots, and the sample was placed 2.8 meters away from the focal lens and perpendicular to the laser beam [47]. The clean fluorescence spectrum induced by femtosecond laser pulse filamentation in air was also ascribed to the low temperature and electron density, which was determined respectively to be $8 \times 10^{17} \mathrm{~cm}^{-3}$ and $6,794 \mathrm{~K}$. Because of the short pulses and the relatively low plasma temperature, the continuum emission associated with the plasma itself, i.e., free-free or free-bound transitions that result from collisions between electrons and ambient gas species and electron-ion recombination in the plasma, is much weaker when compared to conventional ns-LIBS [47].

Figure 2. Filament-induced lead spectrum recorded with a Lidar configuration. The sample was located at $2.8 \mathrm{~m}$ away from the focal lens, and the gate width of the ICCD detector was $2 \mu \mathrm{s}$ and the delay time was $-3 \mathrm{~ns}$ with regard to the laser arriving time on the lead target. As an example, several strong lines in the spectrum are assigned to $\mathrm{Pb} \mathrm{I}$.

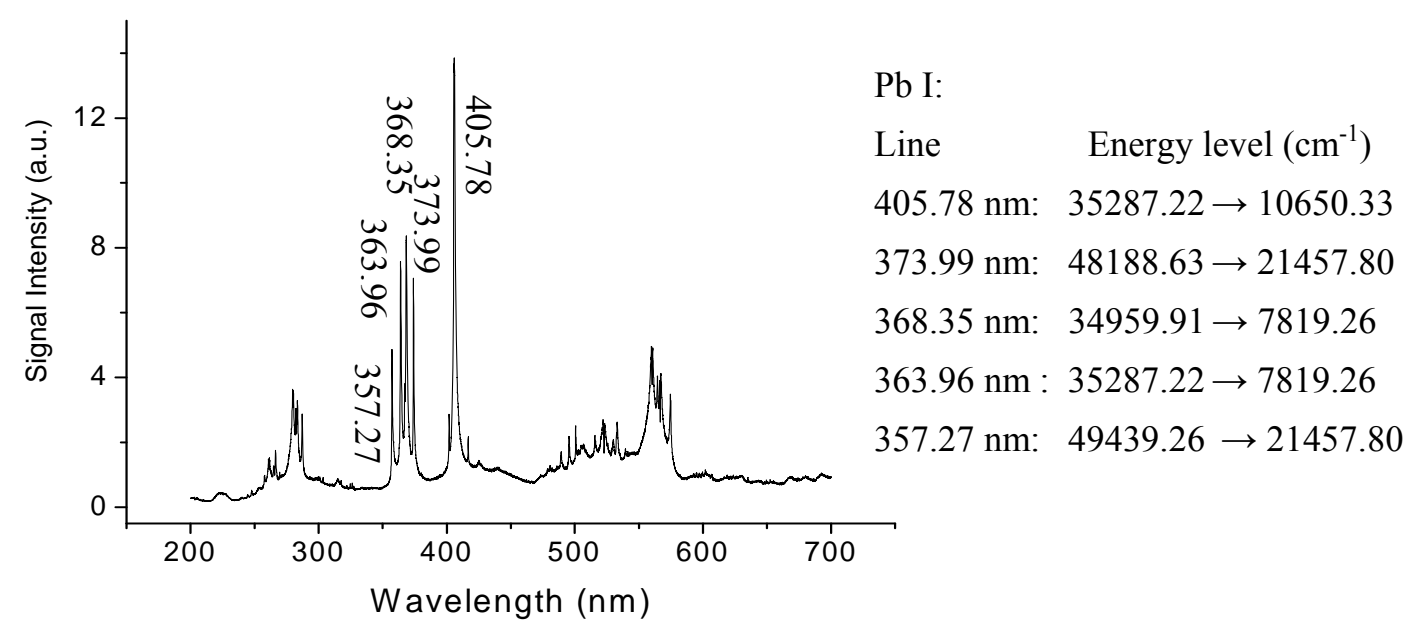

Thus, filamentation together with clean fluorescence constitutes the key towards identifying various targets (gases, solids or aerosols) with very good resolution using only one laser.

\subsection{Application to Samples in Gas Phases}

\subsubsection{Detection and identification of gas molecules}

The clean fluorescence spectra were later demonstrated from the emission of fragments of fluorine-containing halocarbons, notably $\mathrm{HCFC}-124, \mathrm{CF}_{4}$ and $\mathrm{C}_{2} \mathrm{~F}_{6}$, mixed with air in a cell at atmospheric pressure [17]. Subsequently, simultaneous detection and identification of two unknowns 
(using methane and acetylene as test targets) mixed with air at atmospheric pressure were performed using filament-induced nonlinear spectroscopy (FINS) [67]. A genetic algorithm was used to identify the unknown spectra with the premise that the spectral database including the spectral signatures and the strengths of the signals of the corresponding trace species was built, as shown in Figure 3. It was found that the detection sensitivity could reach the ppm to ppb level, depending on the induced fluorescence efficiency from the molecules.

Figure 3. Filament-induced fluorescence spectrum of air containing $1,316 \mathrm{ppm}$ of $\mathrm{C}_{2} \mathrm{H}_{2}$ and 5,263 ppm of $\mathrm{CH}_{4}$ with the fit spectrum by a genetic algorithm under the assumption that the trace species and concentrations in the mixture are unknown. The fit spectrum is shifted in order to facilitate the observation. The inset shows part of the experimental and fitting spectra in a higher resolution. The calculated concentrations of acetylene and methane are 1,592 and 6,342 ppm, respectively. The spectra shown in Figure 3 come from the mixture of air, $\mathrm{C}_{2} \mathrm{H}_{2}$ and $\mathrm{CH}_{4}$. Some spectral lines such as $\mathrm{CH}$ result both from $\mathrm{C}_{2} \mathrm{H}_{2}$ and $\mathrm{CH}_{4}$ [67].

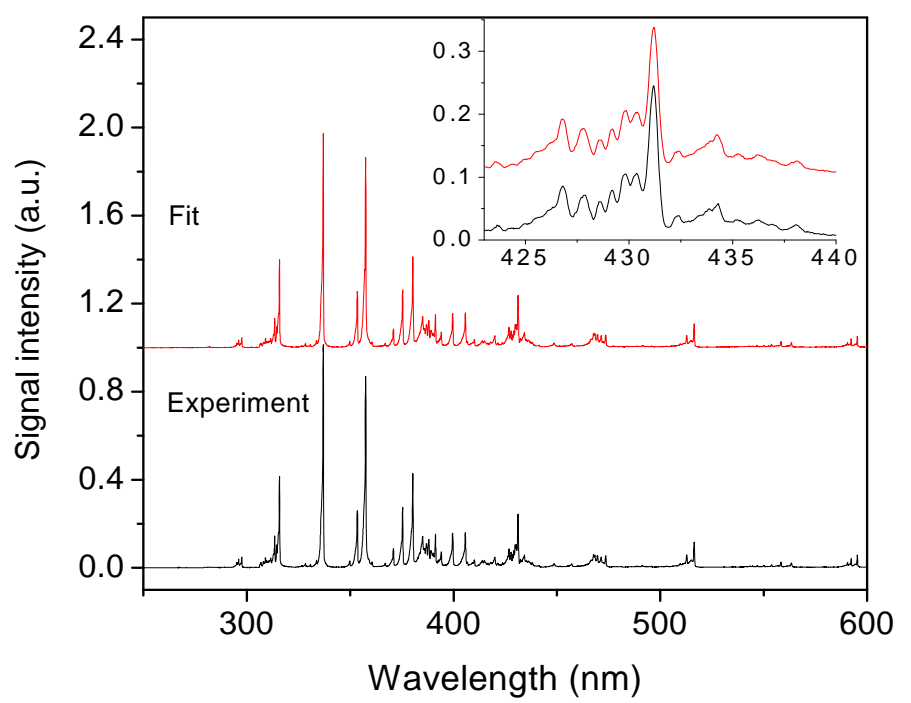

The fluorescence emissions from a variety of hydrocarbon molecules were theoretically attributed to the neutral dissociation of parent molecules via superexcited states, i.e., states beyond the ionization limit, created by multiphoton/tunnel excitation [68]. The idea of neutral dissociation of superexcited states as one of the possible mechanisms responsible for the fluorescence emissions was experimentally confirmed by using a pump-probe technique [69]. When an infrared $1338 \mathrm{~nm}$ laser was used as the probe, an unambiguous reduction of the $\mathrm{CH}$ fluorescence signal dissociated from $\mathrm{CH}_{4}$ was observed, which was attributed to the de-excitation of the super-excited states of $\mathrm{CH}_{4}$ by the probe laser pulse. The lifetime of the super-excited state of $\mathrm{CH}_{4}$ was measured to be about 160 fs.

Remotely, using the FINS technique, the fluorescence emission of nitrogen molecules from the plasma-filament has been extensively studied, not only for the purpose of remote sensing [70,71], but also for characterizing the plasma filament $[64,65,72,73]$. For gas samples, the FINS technique has so far been applied to $\mathrm{CH}_{4}, \mathrm{C}_{2} \mathrm{H}_{2}, \mathrm{C}_{2} \mathrm{H}_{4}$, ethanol vapor and smoke (from burning mosquito coils in air) [74-78]. For the greenhouse gas, methane [74], well resolved backward fluorescence from dissociated $\mathrm{CH}$ radicals measured from a distance of a few meters was used to quantitatively analyze 
the concentration of $\mathrm{CH}_{4}$ as well as its remote detection limit (Figure 4). Based on the experimental results, it was estimated that the concentration sensitivity could be down to the ppm range, and the detection range limit could extend up to the kilometer range. Subsequently, in order to perform such experiments in open-air condition, ethanol was selected as the sample since it is not harmful for human health as compared to most of the hydrocarbon molecules which are toxic and unsuitable. In the ethanol vapor experiment [75], backward fluorescence emission of the ethanol concentration at $0.8 \%$ could be clearly observed at a distance of 30 meters using a simple telescope system.

Figure 4. Filament-induced fluorescence spectrum of mixture of $\mathrm{CH}_{4}$ and air with a $\mathrm{CH}_{4}$ concentration of $2.6 \%$ (v./v.). The inset (a) shows the spectrum in a higher resolution (top), the spectrum of pure air in atmospheric pressure (middle), and the subtraction of the mixture and pure air spectra (bottom). The band results from the $\mathrm{A}^{2} \Delta-\mathrm{X}^{2} \Pi$ transition of $\mathrm{CH}$. The inset (b) shows the extrapolation of the detection limit according to the LIDAR equation $\left(I=L / R^{2}\right.$, where $I$ is the signal intensity, $L$ the effective filament length and $R$ the distance between the end of the filament and the detector). The $3 \sigma$ detection limit was about $0.9 \mathrm{~km}$ for the $\mathrm{CH}_{4}$ concentration of $5 \%$ and the filament length of $20 \mathrm{~m}$, where $\sigma$ is the standard deviation of the background level.

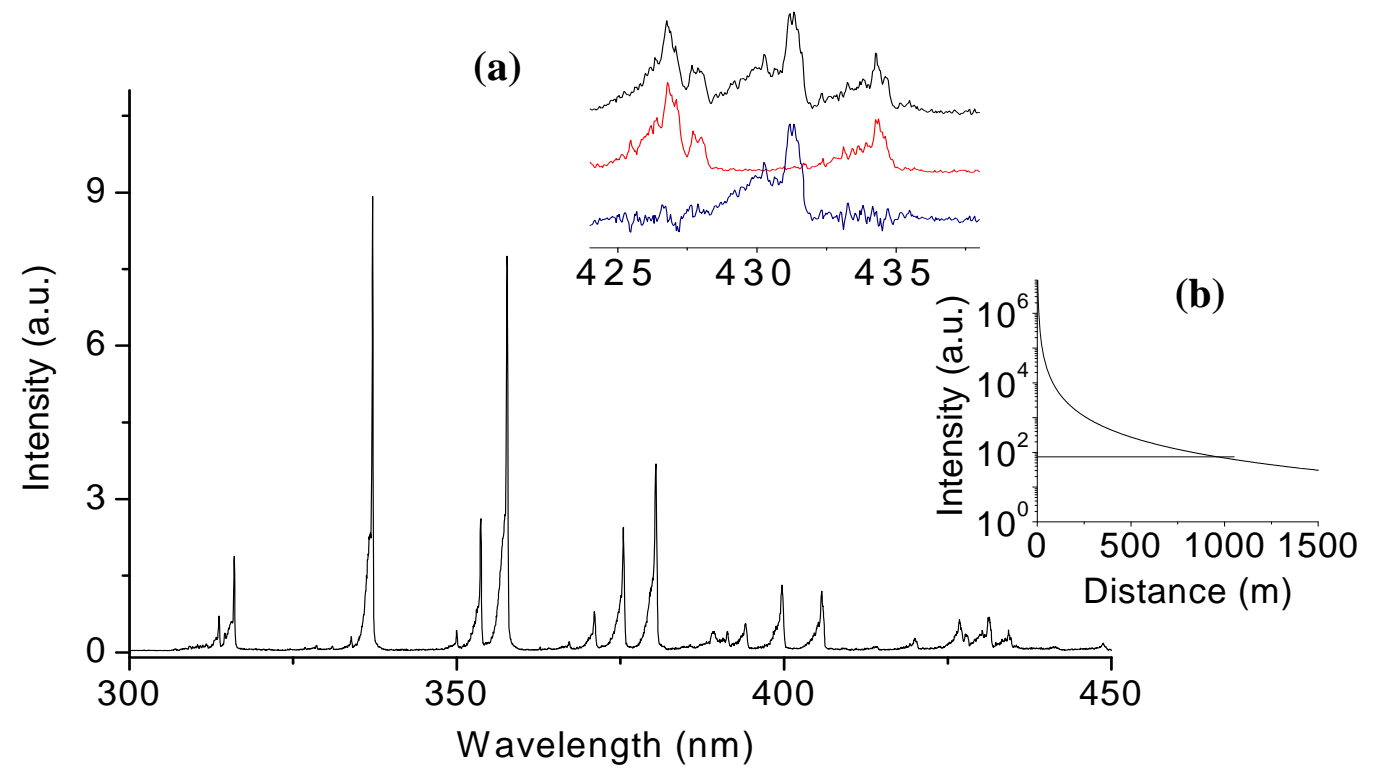

Recently, the remote FINS technique was used to probe a cloud of smoke, which was produced from burning mosquito coils located at a distance of $25 \mathrm{~m}$ from the laser source and LIDAR detector [76]. $\mathrm{CN}, \mathrm{CH}$ and $\mathrm{C}_{2}$ molecular fragments were identified in the sample. Most recently, remote sensing of trace methane using FINS was performed in an open field atmosphere during daytime (with strong sun light) [77]. From the comparison of the results of the laboratory and the open field, it seems that the deterioration of the filaments from the atmospheric turbulence, the profile of the laser beam, combined with the varying sunlight background decreased the efficiency to detect the $\mathrm{CH}$ fluorescence by a factor of only three to four between the laboratory experiment and the field experiment. In addition, the remote detection of the mixture of $\mathrm{CH}_{4}, \mathrm{C}_{2} \mathrm{H}_{2}$ and $\mathrm{C}_{2} \mathrm{H}_{4}$ at 118 m distance was performed [78]. The measurements mentioned above were performed with a single near-infrared 
femtosecond laser, illustrating the possibility to induce characteristic fluorescence from a large number of molecular species. These results open the way to multiple species analysis in atmospheric sensing by combining FINS technique with suitable fluorescence collection systems.

\subsubsection{Stabilization and enhancement of fluorescence}

However, it was noted in the study of remote nitrogen fluorescence spectra induced by the FINS technique that the nitrogen fluorescence signals fluctuate significantly on a shot-to-shot basis despite the rather stable laser pulse energy with an initial large diameter-collimated terawatt level femtosecond laser beam $(\sim 25 \mathrm{~mm})$ [54]. It was observed that the signal intensity distribution along the propagation path as well as the starting point of the filamentation varies randomly. This was mainly ascribed to the competition among different filaments [79], which originate from inhomogeneous intensity distribution in the transverse cross section of the laser pulse due to either initial laser imperfections arising from the source itself or during the propagation through any non-homogeneous optical medium. These ultimately lead to the formation of multiple filaments that are co-propagating in air [79-83]. Since in atmospheric remote sensing it is of particular importance to increase the signal-tonoise ratio, it is necessary to overcome such fluctuations of fluorescence induced by the femtosecond laser filamentation. We will in the following introduce several examples which have been proposed to stabilize and enhance fluorescence signals by controlling the filamentation processes.

The initial laser beam diameter was found to have an effect on the fluorescence signals from nitrogen molecules in air [54,84]. It was observed that when the initial beam diameter of the collimated femtosecond laser pulse was decreased from $25 \mathrm{~mm}$ to $8 \mathrm{~mm}$ by keeping the input laser pulse energy constant the measured backscattered fluorescence signal could be enhanced by three orders of magnitude [54]. Numerical simulations showed that in the small beam there is a faster growth of multiple filaments with propagation distance, a larger average diameter of plasma channels, and a larger overall amount of electrons in the transverse beam section [55]. The increase of the signal and its stability associated with beam squeezing is due to the more effective usage of the background energy in the small beam. On the other hand, it was found that by inserting an iris at the beginning of the propagation path of initially unfocused pulse in air, the $\mathrm{N}_{2}$ fluorescence signal and the length of femtosecond laser filaments formed can be significantly increased when the diameter of an aperture was adjusted to an optimal value [84]. Theoretical 3D+ time stochastic numerical simulations showed that the optimum aperture size corresponds to the case where multiple filaments concentrate around the propagation axis to interfere and form a regularized elongated structure with higher overall amount of plasma.

The fluorescence signals of $\mathrm{N}_{2}$ could also be enhanced by merging the multiple filaments into a geometrical focus [85]. It was found that when a terawatt level laser pulse propagates in air some hot spots in the beam profile are unavoidable to self-focus in air at a short distance. By using a telescope to enlarge the diameter of the initial laser beam, thus enlarging that of the hot spots, such early self-focusing could be overcome. In this manner, the effective focal length of the laser beam can be controlled to be much shorter than the self-focusing distance of both the enlarged beam and the hot spots, leading to the merging of multiple filaments into the geometrical focus. Since in this experimental scheme filamentation starts near the geometrical focus and the beam size is small at this position, the more effective usage of the background energy in the smaller beam results in consistent 
and strong nitrogen fluorescence signals. The control of femtosecond laser filamentation by a telescope was also performed by another group in [86].

Similarly, the fluorescence emission of $\mathrm{N}_{2}$ was found to be significantly enhanced by modifying the initial divergence of the laser pulse using adaptive optics [78,87]. A specially designed focusing telescope including a deformable mirror that corrects the wavefront's aberrations working in a closed loop system with a wavefront sensor can deliver laser pulses over long distances and generate powerful filaments. The collapse distance increases with the beam divergence. Using this configuration, strong nitrogen signal was generated at a distance as far as 90 meters using $40 \mathrm{~mJ}$ laser pulses [87]. This technique was also used for detecting the $\mathrm{CH}_{4}$ and $\mathrm{C}_{2} \mathrm{H}_{2}$ samples at a distance of about 110 meters from the focusing beam expander [78].

For the detection and identification of trace gas in air, one should overcome the spectral interference arising from the $\mathrm{N}_{2}$ fluorescence. It was found that the characteristic fluorescence of atmospheric pollutants usually has a lifetime longer than that of nitrogen and the pollutant fluorescence could thus be isolated from the background such as the nitrogen fluorescence by temporal gating in the detection [17,67]. This technique is certainly at the expense of a reduction in the fluorescence detection sensitivity but with a substantial gain in signal-to-background ratio. Besides the time-resolved measurements, it is also possible to first record the background reference signals without the pollutants, and then obtain the clean fluorescence spectrum of pollutant molecules by removing the reference signals. In this case, the detection sensitivity will not be influenced, as presented in [67]. Moreover, another major noise source for the detection of pollutants using the filamentation-induced fluorescence technique is the self-transformed white light laser (supercontinuum) as a result of the filamentation process [44]. The white light may mask the fluorescence signals generated by the pollutant being targeted. However, it was experimentally shown that the fluorescence spectrum emitted inside the filament could be distinguished from the backscattered supercontinuum both spectrally and temporally over a long range in atmospheric air $[85,88]$ by generating strong and short filaments at a remote focus [85].

\subsection{Application to Solid Targets}

LIBS (laser-induced breakdown spectroscopy) using femtosecond laser pulses called fs-LIBS has recently attracted much attention because of its promising properties, including lower ablation energy threshold, low continuum emission, higher sensitivity, and improved detection precision. However, most fs-LIBS experiments were performed with tightly focused laser beams only at short distances (see e.g., [89-91]). The high intensity $\left(\sim 5 \times 10^{13} \mathrm{~W} / \mathrm{cm}^{2}\right)$ in the filament can remotely ablate the solid target into a small plasma, which emits the fluorescence from excited atoms, ions or molecular fragments. Since 2004, remote filament-induced breakdown spectroscopy (R-FIBS), a special configuration of fsLIBS, has been developed for remote elemental analysis of metallic [28,92] as well as biological samples [93].

\subsubsection{Detection and identification of metallic samples}

Using R-FIBS, the fluorescence spectra of copper $(\mathrm{Cu})$ and iron $(\mathrm{Fe})$ targets located at a distances of 90 meters were first obtained [28], and later the fluorescence emission of the $\mathrm{Cu}$ target placed at a 
distance up to 180 meters was demonstrated [94]. The results showed main features of filament-induced ablation on the surface of metallic samples and associated plasma emission. The R-FIBS technique was also used to detect aluminum and lead samples with a telescope and adaptive mirror as the laser sending systems at a distance of 50 and 118 meters, respectively [78,92]. Besides using the infrared $800 \mathrm{~nm}$ laser as the light source, similar experimental demonstration of R-FIBS using UV laser at $248 \mathrm{~nm}$ with pulse duration of $450 \mathrm{fs}$ and energy of up to $20 \mathrm{~mJ}$ was performed for the detection and identification of brass, lead and different types of stones related to the objects of cultural heritage [95]. These observations revealed the remarkable property of FIBS for the detection and identification of pollutants over a long distance independently of the diffraction limit of laser beam.

\subsubsection{Detection and identification of chemical and biological targets}

The R-LIBS technique has also been applied for the detection of solid chemical-biological samples. The remarkably distinct spectra of egg white and yeast powders located $3.5 \mathrm{~m}$ away from the detection system were experimentally shown in [93] by using the FIBS technique. The same fluorescence spectrum of yeast has also been obtained successfully when the sample was located at a distance of 50 meters from the laser source as well as the detection system. In particular, by using the FIBS technique, the feasibility of remote detection and differentiation of some very similar agriculture related bioaerosols, namely barley, corn, and wheat grain dusts was also demonstrated [29]. All the species showed identical spectra, namely those from molecular $\mathrm{C}_{2}$ and $\mathrm{CN}$ bands, as well as atomic $\mathrm{Si}$, $\mathrm{C}, \mathrm{Mg}, \mathrm{Al}, \mathrm{Na}, \mathrm{Ca}, \mathrm{Mn}, \mathrm{Fe}, \mathrm{Sr}$ and $\mathrm{K}$ lines. These identical spectral bands and lines reveal similar chemical compositions; however, the relative intensities of the spectra are different showing different element abundances from these three bio-targets. The intensity ratios of different elemental lines were used to distinguish these three samples, as shown in Figure 5.

Figure 5. An example of FIBS spectra in the ranges of 270-295 nm and 370-410 nm obtained from the barley, corn and wheat grain dusts with the delay of $t=60 \mathrm{~ns}$ with respect to the laser pulse on the target $(t=0)$. Laser pulse energy was $7 \mathrm{~mJ}$ and the ICCD gate width was $2 \mu \mathrm{s}$. The $\mathrm{Mn}, \mathrm{Si}$, and $\mathrm{Al}$ lines resulting from the three samples show a large difference in signal intensities.

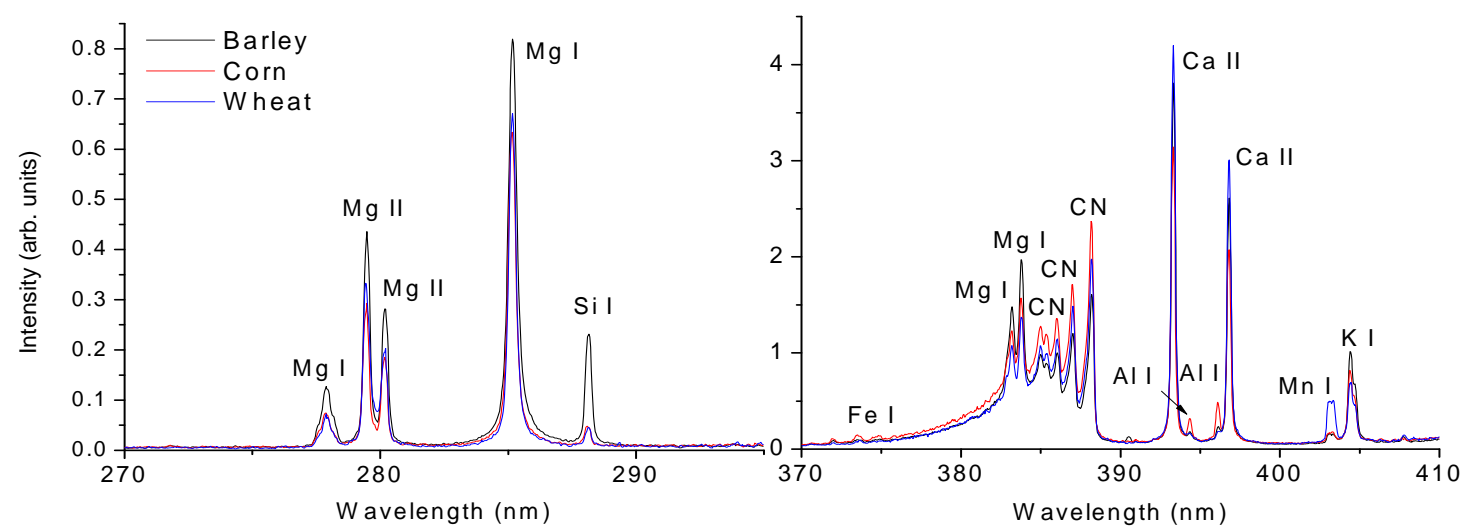

Using R-FIBS, dinitrotoluene (DNT) and ammonium perchlorate samples were detected [96], in which the filament-induced fluorescence signals of these materials were produced both by IR (100 fs) 
and UV lasers (200 ps). Comparison demonstrated that the UV filaments appear to have marked advantages in being able to capture clear spectroscopic signatures of these two materials, in addition to propagating over longer distances. R-FIBS was also used to measure the carbon/clay ratios between three graphite composites of different hardness at a standoff distance of 6 meters [97]. This measurement was performed using both R-FIBS and femtosecond laser induced breakdown (fs-LIBS), and it was found that these two methods revealed similar selectivity and ability to excite emission, but the R-FIBS technique produced more accurate results than those produced by fs-LIBS (tightly focused beam). This was ascribed to the intensity clamping nature of the filament produced in the R-FIBS technique.

\subsubsection{Stabilization and enhancement of fluorescence from solid targets}

For solid target detection, it was shown that the continuum emission in the fluorescence spectra associated mainly with the white light due to the filamentation in ambient air can be significantly reduced by moving the starting point of the filament with respect to the target surface [47]. This was because the spectral broadening of the supercontinuum develops progressively along the self-induced plasma column in air and the broad backscattered supercontinuum only becomes fully developed at the end of a long plasma column, which is the result of the distance-cumulative effects of self-phase modulation and self-steepening of the fundamental laser pulse [31]. On the other hand, using time-resolved measurement, the filamentation-induced white light noise can be easily minimized [93].

It was also possible to obtain clean fluorescence by using a telescope as sending optics system. It was shown that the telescope adjusted by varying the relative distance between the divergent and convergent optical components could greatly improve the performance of remote FIBS (R-FIBS) of aluminum targets [92]. The filaments generated were short, resulting in a negligible white light continuum, and finally, realizing a non-gated R-FIBS measurement (Figure 6). In addition, using a

Figure 6. R-FIBS spectrum taken for aluminum sample located $50 \mathrm{~m}$ away. The gate width of the ICCD detector was set to $20 \mu$ s and the gate was opened $33 \mathrm{~ns}$ before the laser pulse arrived at the target.

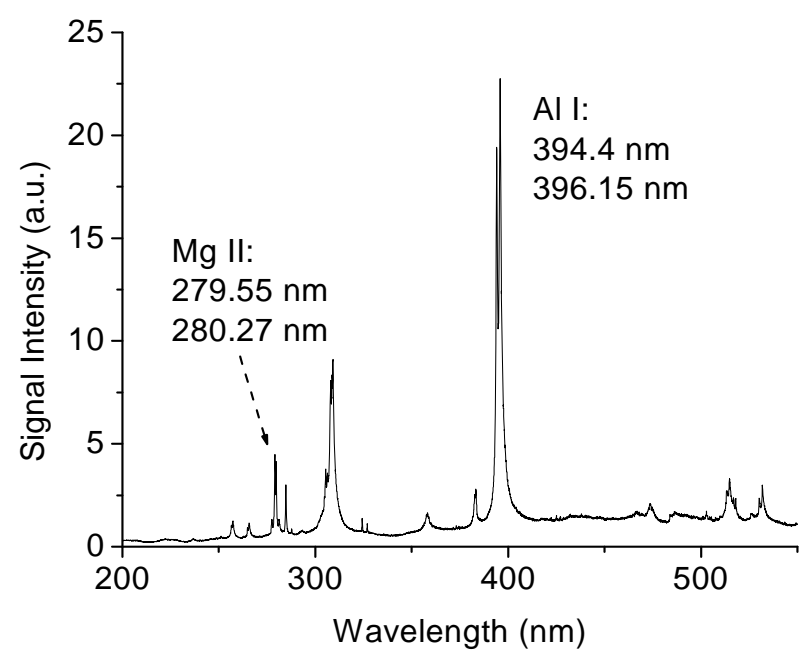

specially designed focusing telescope with a deformable mirror included [78], the laser pulse could be properly deliver the laser pulses over long distances and generate powerful filaments by correcting the 
wavefront's aberrations working in a closed loop system with a wavefront sensor by the deformable mirror. Using this configuration, strong lead signal was generated at a distance as far as $118 \mathrm{~m}$ using $80 \mathrm{~mJ} / 5 \mathrm{ps}$ negatively chirped pulses [78].

\subsection{Application to Water Aerosols Containing Metallic Salts}

Femtosecond laser filamentation in air was also used for probing a cloud of microdroplets in which table salt was dissolved [46,98,99]. By using R-FIBS with Laser pulses of 70 fs duration and $130 \mathrm{~mJ}$ energy, Na fluorescence was observed remotely at a distance of $16 \mathrm{~m}$ [98]. It was further demonstrated that the fluorescence emission of the saltwater aerosols located up to $70 \mathrm{~m}$ away from the LIDAR mirror could be clearly observed by R-FIBS using negatively chirped $10 \mathrm{ps} / 72 \mathrm{~mJ}$ pulses with the telescope designed in [94] as sending optics [46]. It was found that the R-FIBS technique was sensitive to the solvent as well. Four hydrogen bands from the Balmer series were observed in aqueous microdroplet cloud after $\mathrm{H}_{2} \mathrm{O}$ molecules were exploded inside the filaments. Additionally, a cloud of aqueous aerosols containing a mixture of $\mathrm{PbCl}_{2}, \mathrm{CuCl}_{2}, \mathrm{FeCl}_{2}$ and $\mathrm{NaCl}$ were detected using R-FIBS [99]. It was found that fluorescence from all the metallic ions dissolved could be well observed. Moreover, these spectrally narrow atomic transitions excited in the low density plasma did not show any signal overlap. Using the adaptive optics, the fluorescence signals from the aerosol target located 118 meters away from the laser sending systems were observed [78]. These observations exhibited by the characteristic fluorescence of different trace constituents give a good idea of the great potential of the technique for real application remote sensing of aerosols.

Using femtosecond terawatt laser system, riboflavin-containing biological aerosols at a 45-m distance were also detected [100]. However, in this case, the laser intensity in the interaction zone was kept at a level of $10^{11} \mathrm{~W} / \mathrm{cm}^{2}$ to induce two-photon excited fluorescence of riboflavin. This intensity was two orders of magnitude lower than the clamped intensity inside the filament. It was also demonstrated that for multiphoton induced processes such as multi-photon excited fluorescence [101] and multi-photon ionization [102], the emitted light from the particles was strongly enhanced in the backward direction. This is obviously very advantageous for Lidar remote sensing, since it compensates to a certain extent the decrease in sensitively. This phenomenon was understood as a manifestation of the time-reversal principle. Interestingly, it was also shown that the backward fluorescence of nitrogen molecules and ions generated from femtosecond laser-induced filaments shows an exponential increase with increasing filament length, indicating amplified spontaneous emission [103]. The existence of the gain in the backscattered fluorescence from the filament is particularly important for remote-sensing applications. It is expected that the fluorescence from other molecules inside the filament will undergo amplification as well. This is because from our recent work, the fluorescence coming from neutral fragments of more complex molecules such as $\mathrm{CH}_{4}, \mathrm{O}_{2}$, etc. is the result of neutral dissociation through super-excited states [68,69,104,105]. These fluorescing fragments are initially excited at birth (fragmentation) and hence, the population is inverted which should give rise to ASE along the filament (forward and backward). Another way for aerosol Lidar detection using intense femtosecond lasers is to utilize the second and third harmonic generation [106-108] for remote sizing and electric charge measurements on cloud droplets. 


\section{Femtosecond Filamentation-Based White-Light Techniques}

The white-light spectrum induced by femtosecond laser filamentation can span from the ultraviolet (UV) to the infrared (IR) (supercontinuum) (see e.g., [7-12] and reference therein). This broadband white light makes it an ideal source for application in remote sensing of multiple constituents in air by combining white light absorption spectroscopy with Lidar technique [45,109], as well as by the scattering of white light [110].

\subsection{White-Light Absorption Lidar}

With the white-light Lidar technique, the absorption spectra of oxygen and water vapor in the atmosphere were shown by using the supercontinuum generated by a so-called "Teramobile" system [111]. The spectra were recorded in the range of visible to near-infrared $850 \mathrm{~nm}$, and the detection was reached up to the distance of $1.1 \mathrm{~km}$ [112]. It was found from a comparison between the experimental results and the tabulated spectroscopic data that an excellent correlation with measurements was made on water vapor whereas observations on the oxygen showed discrepancy. Subsequently, the Lidar signals of the supercontinuum in the near-infrared were obtained [32]. A signal up to $4 \mathrm{~km}$ in altitude, in the band $1-1.7 \mu \mathrm{m}$, was collected using a 2-m astronomical telescope. A

10-fold enhancement of the infrared signal backscattered from the atmosphere compared with that expected using a previously measured laboratory spectrum was observed, which suggested a more efficient frequency conversion into the infrared under long-distance propagation conditions. It was also shown that the temperature and humidity of atmosphere at the altitude of $4.5 \mathrm{~km}$ above the ground level could be determined by analyzing the range-integrated spectra of the backscattered white-light continuum between 680 and $920 \mathrm{~nm}$, which covered the rotational-vibrational band of $\mathrm{H}_{2} \mathrm{O}$ centered at $820 \mathrm{~nm}$, as well as the $\mathrm{O}_{2} \mathrm{~A}$ band around $762 \mathrm{~nm}$, showing the ability of multi-parameter analysis of the cloud microphysics by the white-light differential absorption Lidar [113]. In addition, the distribution of the ozone $\left(\mathrm{O}_{3}\right)$ concentration in the range of 500-1,200 $\mathrm{m}$ in the atmosphere was monitored at different time of a day using the teramobile system [114].

The feasibility of the filamentation-induced white light continuum for application to remote sensing of trace gases in air was recently tested in the laboratory. The white light continuum in a broad wavelength range from 300 to more than 2,200 nm generated by the filamentation of femtosecond laser pulses in a $\mathrm{Kr}$ gas cell was used to perform direct absorption spectroscopy of $\mathrm{CO}_{2}$ at around $2,000 \mathrm{~nm}$ in a laboratory 9-meter absorption cell [115]. The absorption spectrum from 1,100 to 2,200 $\mathrm{nm}$ was shown. It was estimated from the absorption band at $2005 \mathrm{~nm}$ that the measured $\mathrm{CO}_{2}$ concentrations could reach to an accuracy of 1-2 ppm from the signals collected for the atmospheric optical length of around $5.5 \mathrm{~km}$ through the air.

\subsection{White Light Scattering}

Aerosol and cloud layers in the atmosphere could be detected by scattering the white light generated from the filamentation of femtosecond laser pulses in optical media [116]. It was shown that strong signals from an aerosol layer (from 0.5 to $2 \mathrm{~km}$ ) and a cumulus cloud layer (from 2.2 to $2.3 \mathrm{~km}$ ) 
could be observed on the three channels of 350, 550, and $700 \mathrm{~nm}$ with the white light source spanned from 300 to $950 \mathrm{~nm}$ generated by the filamentation of femtosecond laser pulses in a 9-meter-long krypton tube [116]. The channel with the longer wavelength of $700 \mathrm{~nm}$ showed a higher capacity to distinguish the aerosol layer when compared to the $350 \mathrm{~nm}$ channel. Subsequently, utilizing the polarization property of the coherent white light continuum, the depolarization remote sensing of aerosol and cloud layers with the channel of $450 \mathrm{~nm}$ was performed and backscattered signals corresponding to 0.6 and $1.0 \mathrm{~km}$ in height from running clouds were observed [117]. Moreover, simultaneous three-wavelength depolarization measurements of cloud and aerosol at 450, 550, and $800 \mathrm{~nm}$ were tested [110], and used to detect the Asian dust particles [118]. It was also shown that particle size and density of water droplets within the cloud could be extracted from the angular multiple scattering profiles of the white-light continuum generated by the filamentation in air [113].

\section{Summary}

In this article, we have reviewed the representative results of remote sensing of atmosphere by techniques based on femtosecond laser filamentation phenomena. The samples include gases, powders, smoke, water aerosols containing multiple solutes, metallic targets, water droplets within the cloud. Experimental techniques include filament-induced characteristic non-linear fluorescence of gases, filament-induced breakdown spectroscopy, white-light absorption Lidar, and multiple scattering of white light continuum. Based on the experimental evidences, we may conclude that a single laser is sufficient to induce the characteristic fluorescence and to obtain absorption bands for a large number of molecular species, showing the possibility of observing many atmospheric constituents of interest. This allows us to qualify the femtosecond laser filamentation as an ideal tool for the detection and identification of atmospheric constituents. This opens up a new pathway towards remote detection of targets related to safety, security and pollution as well as global environmental monitoring such as greenhouse gases.

The size of ultrafast laser sources is constantly shrinking and thus, relatively compact femtosecond remote sensing systems are possible for practical applications. However, most of the experiments presented using filament-induced fluorescence techniques were performed in a laboratory scale. While the white light-based techniques were carried out in outdoor environment, the samples were limited to water droplets and oxygen. This requires much more effort to confirm the precision and reliability of different filamentation-based techniques and to clarify their practical application scopes. In particular, for filamentation-induced fingerprint fluorescence spectra, in view of the complexity of biological matters and of fragmentary knowledge, there are still many challenges ahead not only for practical applications, but also for understanding the underlying physics and chemistry.

\section{Acknowledgements}

This work was supported in part by Natural Sciences and Engineering Research Council, Defence Research and Development Canada-Valcartier, Canada Foundation for Innovation, FQRNT, Canada Research Chairs, China NSFC 11074098 and NCET-09-0429. 


\section{References and Notes}

1. Svanberg, S. Differential absorption Lidar (DIAL). In Air Monitoring by Spectroscopic Techniques; Sigrist, M.W., Ed.; Wiley: New York, NY, USA, 1994; pp. 85-162.

2. Measures, R.M. Laser Remote Sensing: Fundamentals and Applications; Wiley: New York, NY, USA, 1984.

3. Schiff, H.I.; Mackay, G.I.; Bechara, J. The use of tunable diode laser absorption spectroscopy for atmospheric measurements. In Air Monitoring by Spectroscopic Techniques; Sigrist, M.W., Ed.; Wiley: New York, NY, USA, 1994; pp. 239-335.

4. Lee, W.B.; Wu, J.Y.; Lee, Y.I.; Sneddon, J. Recent applications of laser-induced breakdown spectrometry: A review of material approaches. Appl. Spectrosc. Rev. 2004, 39, 27-97.

5. Morel, S.; Leone, N.; Adam, P.; Amouroux, J. Detection of bacteria by time-resolved laser-induced breakdown spectroscopy. Appl. Opt. 2003, 42, 6184-6191.

6. Munson, C.A.; De Lucia, F.C.; Piehler, T.; McNesby, K.L.; Miziolek, A.W. Investigation of statistics strategies for improving the discriminating power of laser-induced breakdown spectroscopy for chemical and biological warfare agent simulants. Spectrochim. Acta Part B 2005, 60, 1217-1224.

7. Chin, S.L.; Hosseini, S.A.; Liu, W.; Luo, Q.; Théberge, F.; Aközbek, N.; Becker, A.; Kandidov, V.P.; Kosareva, O.G.; Schroeder, H. The propagation of powerful femtosecond laser pulses in optical media: Physics, applications, and new challenges. Can. J. Phys. 2005, 83, 863905.

8. Couairon, A.; Mysyrowicz, A. Femtosecond filamentation in transparent media. Phys. Rep. 2007, 441, 47-189.

9. Berge, L.; Skupin, S.; Nuter, R.; Kasparian, J.; Wolf, J.-P. Ultrashort filaments of light in weakly ionized, optically transparent media. Rep. Prog. Phys. 2007, 70, 1633-1713.

10. Kasparian, J.; Wolf, J.-P. Physics and applications of atmospheric nonlinear optics and filamentation. Opt. Exp. 2008, 16, 466-493.

11. Kandidov, V.P.; Shlenov, S.A.; Kosareva, O.G. Filamentation of high-power femtosecond laser radiation. Quan. Electron. 2009, 39, 205-228.

12. Chin, S.L. Femtosecond Laser Filamentation, 1st ed.; Springer: New York, NY, USA, 2010; pp. 1-124.

13. Lange, H.R.; Chiron, A.; Ripoche, J.-F.; Mysyrowicz, A.; Breger, P.; Agostini, P. High order harmonic generation and quasi-phase matching in xenon using self-guided femtosecond laser pulses. Phys. Rev. Lett. 1998, 81, 1611-1613.

14. Becker, A.; Aközbek, N.; Vijayalakshmi, K.; Oral, E.; Bowden, C.M.; Chin, S.L. Intensity clamping and re-focusing of intense femtosecond laser pulses in nitrogen molecular gas. Appl. Phys. B 2001, 73, 287-290.

15. Kasparian, J.; Sauerbrey, R.; Chin, S.L. The critical laser intensity of self-guided light filaments in air. Appl. Phys. B 2000, 71, 877-879.

16. Talebpour, A.; Abdel-Fattah, M.; Bandrauk, A.D.; Chin, S.L. Spectroscopy of the gases interacting with intense femtosecond laser pulses. Laser Phys. 2007, 11, 68-76. 
17. Gravel, J.-F.; Luo, Q.; Boudreau, D.; Tang, X.P.; Chin, S.L.; Sensing of halocarbons using femtosecond laser-induced fluorescence. Anal. Chem. 2004, 76, 4799-4805.

18. Aközbek, N.; Iwasaki, A.; Becker, A.; Scalora, M.; Chin, S.L.; Bowden, C.M. Third-harmonic generation and self-channeling in air using high-power femtosecond laser pulses. Phys. Rev. Lett. 2002, 89, 143901(1-4).

19. Kortsalioudakis, N.; Tatarakis, M.; Vakakis, N.; Moustaizis, S.D.; Franco, M.; Prade, B.; Mysyrowicz, A.; Papadogiannis, N.A.; Couairon, A.; Tzortzakis, S. Enhanced harmonic conversion efficiency in the self-guided propagation of femtosecond ultraviolet laser pulses in argon. Appl. Phys. B 2005, 80, 211-214.

20. Berge, L.; Skupin, S.; Méjean, G.; Kasparian, J.; Yu, J.; Frey, S.; Salmon, E.; Wolf, J.P. Supercontinuum emission and enhanced self-guiding of infrared femtosecond filaments sustained by third-harmonic generation in air. Phys. Rev. E 2005, 71, 016602(1-13).

21. Kolesik, M.; Wright, E.M.; Becker, A.; Moloney, J.V. Simulation of third-harmonic and supercontinuum generation for femtosecond pulses in air. Appl. Phys. B 2006, 85, 531-538.

22. Théberge, F.; Aközbek, N.; Liu, W.; Becker, A.; Chin, S.L. Tunable Ultrashort Laser Pulses Generated through Filamentation in Gases. Phys. Rev. Lett. 2006, 97, 023904(1-4).

23. D’Amico, C.; Houard, A.; Franco, M.; Prade, B.; Mysyrowicz, A.; Couairon, A; Tikhonchuk, V.T. Conical forward THz emission from femtosecond-laser-beam filamentation in air. Phys. Rev. Lett. 2007, 98, 235002 (1-4).

24. Liu, Y.; Houard, A.; Prade, B.; Akturk, S.; Mysyrowicz, A.; Tikhonchuk, V.T. Terahertz radiation source in air based on bifilamentation of femtosecond laser pulses. Phys. Rev. Lett. 2007, 99, 135002(1-4).

25. Wang, T.J.; Chen, Y.; Marceau, C.; Théberge, F.; Châteauneuf, M.; Dubois, J.; Chin, S.L. High energy terahertz emission from two-color laser-induced filamentation in air with pump pulse duration control. Appl. Phys. Lett. 2009, 6, 131108(1-3).

26. Wang, T.J.; Daigle, J.-F.; Chen, Y.; Marceau, C.; Théberge, F.; Châteauneuf, M.; Dubois, J.; Chin. S.L. High energy THz generation from meter-long two-color filaments in air. Laser Phys. Lett. 2010, 7, 517-521.

27. Liu, J.L.; Dai, J.M.; Chin, S.L.; Zhang, X.C. Broadband terahertz wave remote sensing using coherent manipulation of fluorescence from asymmetrically ionized gases. Nature Photon. 2010, 4, 627-631.

28. Stelmaszczyk, K.; Rohwetter, P.; Méjean, G.; Yu, J.; Salmon, E.; Kasparian, J.; Ackermann, R.; Wolf, J.P.; Wöste, L. Long-distance remote laser-induced breakdown spectroscopy using filamentation in air. Appl. Phys. Lett. 2004, 85, 3977-3979.

29. Xu, H.L.; Méjean, G.; Liu, W.; Kamali, Y.; Daigle, J.F.; Azarm, A.; Simard, P.T.; Mathieu, P.; Roy, G.; Simard, J.-R.; Chin, S.L. Remote sensing of similar biological materials using femtosecond filament-induced breakdown spectrocospy. Appl. Phys. B 2007, 87, 151-156.

30. Brodeur, A.; Chin. S.L. Ultrafast white-light continuum generation and self-focusing in transparent condensed media. J. Opt. Soc. Am. B 1999, 16, 637-650.

31. Aközbek, N.; Scalora, M.; Bowden, C.M.; Chin. S.L. White light continuum generation and filamentation during the propagation of ultra-short laser pulses in air. Opt. Commun. 2001, 191, 353-362. 
32. Méjean, G.; Kasparian, J.; Salmon, E.; Yu, J.; Wolf, J.-P.; Bourayou, R.; Sauerbrey, R.; Rodriguez, M.; Wöste, L.; Lehmann, H.; Stecklum, B.; Laux, U.; Eislöffel, J.; Scholz, A.; Hatzes, A.P. Towards a supercontinuum-based infrared lidar. Appl. Phys. B 2003, 77, 357-359.

33. Méjean, G.; Kasparian, J.; Yu, J.; Frey, S.; Salmon, E.; Ackermann, R.; Wolf, J.P.; Bergé, L.; Skupin, S. UV-supercontinuum generated by femtosecond pulse filamentation in air: Meterrange experiments versus numerical simulations. Appl. Phys. B 2006, 83, 341-345.

34. Théberge, F.; Liu, W.; Luo, Q.; Chin, S.L. Ultrabroadband continuum generated in air (down to $230 \mathrm{~nm}$ ) using ultrashort and intense laser pulses. Appl. Phys. B 2005, 80, 221-225.

35. Théberge, F.; Châteauneuf, M.; Ross, V.; Mathieu, P.; Dubois, J. Ultrabroadband conical emission generated from the ultraviolet up to the far-infrared during the optical filamentation in air. Opt. Lett. 2008, 33, 2515-2517.

36. Yang, G.; Shen, Y. Spectral broadening of ultrashort pulses in a nonlinear medium. Opt. Lett. 1984, 9, 510-512.

37. Gaeta, A.L. Catastrophic collapse of ultrashort pulses. Phys. Rev. Lett. 2000, 84, 3582-3585.

38. Méchain, G.; Méjean, G.; Ackermann, R.; Rohwetter, P.; André, Y.-B.; Kasparian, J.; Prade, B.; Stelmaszczyk, K.; Yu, J.; Salmon, E.; Winn, W.; Schlie, L.A.; Mysyrowicz, A.; Sauerbrey, R.; Wöste, L.; Wolf, J.-P. Propagation of fs TW laser filaments in adverse atmospheric conditions. Appl. Phys. B 2005, 80, 785-789.

39. Chin, S.L.; Talebpour, A.; Yang, J.; Petit, S.; Kandidov, V.P.; Kosareva, O.G.; Tamarov, M.P. Filamentation of femtosecond laser pulses in the turbulent air. Appl. Phys. B 2002, 74, 67-76.

40. Ackermann, R.; Méjean, G.; Kasparian, J.; Yu, J.; Salmon, E.; Wolf, J.-P. Laser filaments generated and transmitted in highly turbulent air. Opt. Lett. 2006, 31, 86-88.

41. Salame, R.; Lascoux, N.; Salmon, E.; Ackermann, R.; Kasparian, J.; Wolf, J.P. Propagation of laser filaments through an extended turbulent region. Appl. Phys. Lett. 2007, 91, 171106(1-3).

42. Rodriguez, M.; Bourayou, R.; Méjean, G.; Kasparian, J.; Yu, J.; Salmon, E.; Scholz, A.; Stecklum, B.; Eislöffel, J.; Laux, U.; Hatzes, P.; Sauerbrey, R.; Wöste, L.; Wolf, J.-P. Kilometerrange nonlinear propagation of femtosecond laser pulses. Phys. Rev. E 2004, 69, 036607(1-7).

43. Chin, S.L.; Xu, H.L.; Luo, Q.; Théberge, F.; Liu, W.; Daigle, J.F.; Kamali, Y.; Simard, P.T.; Bernhardt, J.; Hosseini, S.A.; Sharifi, M.; Méjean, G.; Azarm, A.; Marceau, C.; Kosareva, O.; Kandidov, V.P.; Aközbek, N.; Becker, A.; Roy, G.; Mathieu, P.; Simard, J.R.; Châteauneuf, M.; Dubois, J. Filamentation "remote" sensing of chemical and biological agents/pollutants using only one femtosecond laser source. Appl. Phys. B 2009, 95, 1-12.

44. Chin, S.L.; Brodeur, A.; Petit, S.; Kosareva, O.G.; Kandidov, V.P. Filamentation and supercontinuum generation during the propagation of powerful ultrashort laser pulses in optical media (white light laser). J. Nonlinear Opt. Phys. Mater. 1999, 8, 121-146.

45. Kasparian, J.; Rodriguez, M.; Méjean, G.; Yu, J.; Salmon, E.; Wille, H.; Bourayou, R.; Frey, S.; Andre, Y.-B.; Mysyrowicz, A.; Sauerbrey, R.; Wolf, J.-P.; Wöste, L. White-light filaments for atmospheric analysis. Science 2003, 301, 61-64.

46. Daigle, J.F. Méjean, G.; Liu, W.; Théberge, F.; Xu, H.L.; Kamali, Y.; Bernhardt, J.; Azarm, A.; Sun, Q.; Mathieu, P.; Roy, G.; Simard, J.R.; Chin, S.L. Long range trace detection in aqueous aerosol using remote filament-induced breakdown spectroscopy. Appl. Phys. B 2007, 87, 749-754. 
47. Xu, H.L.; Bernhardt, J.; Mathieu, P.; Roy, G.; Chin, S.L. Understanding the advantage of remote femtosecond laser-induced spectroscopy of metallic targets. J. Appl. Phys. 2007, 101, 033124(1-6).

48. Chin. S.L. Method for Remote Sensing of Pollutant Molecules in a Transparent Medium Using Ultrashort Intense Lasers. No. US 7184143 B2, February 27, 2007.

49. Marburger, J.H. Self-focusing: Theory. Prog. Quant. Electr. 1975, 4, 35-110.

50. Liu, W.; Chin, S.L. Direct measurement of the critical power of femtosecond Ti:sapphire laser pulse in air. Opt. Exp. 2005, 13, 5750-5755.

51. Liu, W.; Luo, Q.; Theberge, F.; Xu, H.L.; Hosseini, S.A.; Sarifi, S.M.; Chin, S.L. The influence of divergence on the filament length during the propagation of intense ultra-short laser pulses. Appl. Phys. B 2006, 82, 373-376.

52. Mlejnek, M.; Wright, E.M.; Moloney, J.V. Dynamic spatial replenishment of femtosecond pulses propagating in air. Opt. Lett. 1998, 23, 382-384.

53. Mlejnek, M.; Wright, E.M.; Moloney, J.V. Moving-focus versus self-waveguiding model for long-distance propagation of femtosecond pulses in air. IEEE J. Quant. Electron. 1999, 35, 1771-1776.

54. Luo, Q.; Hosseini, S.A.; Liu, W.; Gravel, J.-F.; Kosareva, O.G.; Panov, N.A.; Aközbek, N.; Kandidov, V.P.; Roy, G.; Chin, S.L. Effect of beam diameter on the propagation of intense femtosecond laser pulses. Appl. Phys. B 2005, 80, 35-38.

55. Kosareva, O.G.; Panov, N.A.; Aközbek, N.; Kandidov, V.P,; Luo, Q.; Hosseini, S.A.; Liu, W.; Gravel, J.-F.; Roy, G.; Chin, S.L. Controlling a bunch of multiple filaments by means of a beam diameter. Appl. Phys. B 2006, 82, 111-122.

56. Courvoisier, F.; Boutou, V.; Kasparian, J.; Salmon, E.; Méjean, G.; Yu, J.; Wolf, J.-P. Ultraintense light filaments transmitted through clouds. Appl. Phys. Lett. 2003, 83, 213-215.

57. Dubietis, A.; Kucinskas, E.; Tamosauskas, G.; Gaizauskas, E.; Porras, M.A.; Di Trapani, P. Self-reconstruction of light filaments. Opt. Lett. 2004, 29, 2893-2895.

58. Kolesik, M.; Moloney, J.V. Self-healing femtosecond light filaments. Opt. Lett. 2004, 29, 590-592.

59. Kosareva, O.G.; Kandidov, V.P.; Brodeur, A.; Chien, C.Y.; Chin, S.L. Conical emission from laser-plasma interactions in the filamentation of powerful ultrashort laser pulses in air. Opt. Lett. 1997, 22, 1332-1334.

60. Eisenmann, S.; Penano, J.; Sprangle, P.; Zigler, A. Effect of an energy reservoir on the atmospheric propagation of laser-plasma filaments. Phys. Rev. Lett. 2008, 100, 155003(1-4).

61. Liu, W.; Théberge, F.; Arévalo, E.; Gravel, J.F.; Becker, A.; Chin, S.L. Experiment and simulations on the energy reservoir effect in femtosecond light filaments. Opt. Lett. 2005, 30, 2602-2604.

62. Liu, W.; Gravel, J.-F.; Théberge, F.; Becker, A.; Chin, S.L. Background reservoir: Its crucial role for long-distance propagation of femtosecond laser pulses in air. Appl. Phys. B 2005, 80, $857-860$.

63. Xu, H.L.; Azarm, A.; Bernhardt, J.; Kamali, Y.; Chin, S.L. The mechanism of nitrogen fluorescence inside a femtosecond laser filament in air. Chem. Phys. 2009, 360, 171-175. 
64. Théberge, F.; Liu, W.; Simard, P.-Tr.; Becker, A.; Chin, S.L. Plasma density inside a femtosecond laser filament in air: Strong dependence on external focusing. Phys. Rev. E 2006, 74, 036406(1-7).

65. Bernhardt, J.; Liu, W.; Théberge, F.; Xu, H.L.; Daigle, J.F.; Châteauneuf, M.; Dubois, J.; Chin, S.L. Critical power for self-focussing of a femtosecond laser pulse in helium. Opt. Commun. 2008, 281, 2248-2251.

66. Becker, A.; Bandrauk, A.D.; Chin, S.L. S-matrix analysis of non-resonant multiphoton ionisation of inner-valence electrons of the nitrogen molecule. Chem. Phys. Lett. 2001, 343, 345-350.

67. Xu, H.L.; Kamali, Y.; Marceau, C.; Simard, P.T.; Liu, W.; Bernhardt, J.; Méjean, G.; Mathieu, P.; Roy, G.; Simard, J.-R.; Chin, S.L. Simultaneous detection and identification of multigas pollutants using filament-nduced nonlinear spectroscopy. Appl. Phys. Lett. 2007, 90, 101106(1-3).

68. Kong, F.; Luo, Q.; Xu, H.L.; Sharifi, M.; Song, D.; Chin, S.L. Explosive photodissociation of methane induced by ultrafast intense laser. J. Chem. Phys. 2006, 125, 133320(1-5).

69. Azarm, A.; Xu, H.L.; Kamali, Y.; Bernhardt, J.; Song, D.; Xia, A.; Teranishi, Y.; Lin, S.H.; Kong, F.; Chin, S.L. Direct observation of super-excited states in methane created by a femtosecond intense laser field. J. Phys. B 2008, 41, 225601(1-4).

70. Luo, Q.; Hosseini, S.A.; Ferland, B.; Chin, S.L. Backward time-resolved spectroscopy from filament induced by ultrafast intense laser pulses. Opt. Commun. 2004, 233, 411-416.

71. Luo, Q.; Yu, J.; Hosseini, S.A.; Liu, W.; Ferland, B.; Roy, G.; Chin, S.L. Long-rang detection and length estimation of light filaments using extra-attenuation of terawatt femtosecond laser pulses propagating in air. Appl. Opt. 2005, 44, 391-397.

72. Iwasaki, A.; Aközbek, N.; Ferland, B.; Luo, Q.; Roy, G.; Bowden, C.M.; Chin, S.L. A LIDAR technique to measure the filament length generated by a high-peak power femtosecond laser pulse in air. Appl. Phys. B 2003, 76, 231-236.

73. Hosseini, S.A.; Yu, J.; Luo, Q.; Chin, S.L. Multi-parameter characterization of the longitudinal plasma profile of a filament: a comparative study. Appl. Phys. B 2004, 79, 519-523.

74. Xu, H.L.; Daigle, J.F.; Luo, Q.; Chin, S.L. Femtosecond laser-induced nonlinear spectroscopy for remote sensing of methane. Appl. Phys. B 2006, 82, 655-658.

75. Luo, Q.; Xu, H.L.; Hosseini, S.A.; Daigle, J.F.; Theberge, F.; Sharifi, M.; Chin, S.L. Remote sensing of pollutants using femtosecond laser pulse fluorescence spectroscopy. Appl. Phys. B 2006, 82, 105-109.

76. Daigle, J.-F.; Kamali, Y.; Roy, G.; Chin, S.L. Remote filament-induced fluorescence spectroscopy from thin clouds of smoke. Appl. Phys. B 2008, 93, 759-762.

77. Kamali, Y.; Daigle, J.-F.; Théberge, F.; Châteauneuf, M.; Azarm, A.; Chen, Y.; Marceau, C.; Lessard, S.C.; Lessard, F.; Roy, G.; Dubois, J.; Chin, S.L. Remote sensing of trace methane using mobile femtosecond laser system of T\&T Lab. Opt. Commun. 2009, 282, 2062-2065.

78. Daigle, J.-F.; Kamali, Y.; Châteauneuf, M.; Tremblay, G.; Théberge, F.; Dubois, J.; Roy, G.; Chin, S.L. Remote sensing with intense filaments enhanced by adaptive optics. Appl. Phys. B 2009, 97, 701-713.

79. Hosseini, S.A.; Luo, Q.; Ferland, B.; Liu, W.; Chin, S.L.; Kosareva, O.G.; Panov, N.A.; Aközbek, N.; Kandidov, V.P. Competition of multiple filaments during the propagation of intense femtosecond laser pulses. Phys. Rev. A 2004, 70, 033802(1-12). 
80. Vidal, F.; Johnston, T.W. Electromagnetic beam breakup: Multiple filaments, single beam equilibria, and radiation. Phys. Rev. Lett. 1996, 77, 1282-1285.

81. Mlejnek, M.; Kolesik, M.; Moloney, J.V.; Wright, E.M. Optically turbulent femtosecond light guide in air. Phys. Rev. Lett. 1999, 83, 2938-2941.

82. Méchain, G.; Couairon, A.; Franco, M.; Prade, B.; Mysyrowicz, A. Organizing multiple femtosecond filaments in air. Phys. Rev. Lett. 2004, 93, 035003(1-4).

83. Dubietis, A.; Tamosauskas, G.; Fibich, G.; Ilan, B. Multiple filamentation induced by inputbeam ellipticity. Opt. Lett. 2004, 29, 1126-1128.

84. Daigle, J.-F.; Kosareva, O.; Panov, N.; Bégin, M.; Lessard, F.; Marceau, C.; Kamali, Y.; Roy, G.; Kandidov, V.P.; Chin, S.L. A simple method to significantly increase filaments' length and ionization density. Appl. Phys. B 2009, 94, 249-257.

85. Liu, W.; Theberge, F.; Daigle, J.-F.; Simard, P.T.; Sarifi, S.M.; Kamali, Y.; Xu, H.L.; Chin, S.L. An efficient control of ultrashort laser filament location in air for the purpose of remote sensing. Appl. Phys. B 2006, 85, 55-58.

86. Fibich, G.; Sivan, Y.; Ehrlich, Y.; Louzon, E.; Fraenkel, M.; Eisenmann, S.; Katzir, Y.; Zigler, A. Control of the collapse distance in atmospheric propagation. Opt. Exp. 2006, 14, 4946-4957.

87. Daigle, J.-F.; Kamali, Y.; Bernhardt, J.; Liu, W.; Marceau, C.; Azarm A.; Chin, S.L. Generation of powerful filaments at a long distance using adaptive optics. Opt. Commun. 2008, 281, 3327-3335.

88. Théberge, F.; Liu, W.; Hosseini, S.A.; Luo, Q.; Sharifi, S.M.; Chin, S.L. Long-range spectrally and spatially resolved radiation from filaments in air. Appl. Phys. B 2005, 81, 131-134.

89. Margetic, V.; Pakulev, A.; Stockhaus, A.; Bolshov, M.; Niemax, K.; Hergenröder, R. A comparison of nanosecond and femtosecond laser-induced plasma spectroscopy of brass samples. Spectrochim. Acta Part B 2000, 55, 1771-1185.

90. Eland, K.L.; Stratis, D.N.; Gold, D.M.; Goode, S.R.; Angel, S.M. Energy dependence of emission intensity and temperature in a LIBS plasma using femtosecond excitation. Appl. Spectrosc. 2001, 55, 286-291.

91. Baudelet, M.; Guyon, L.; Yu, J.; Wolf, J.P.; Amodeo, T.; Frejafon, E.; Laloi, P.; Femtosecond time-resolved laser-induced breakdown spectroscopy for detection and identification of bacteria: A comparison to the nanosecond regime. J. Appl. Phys. 2006, 99, 084701(1-9).

92. Liu, W.; Xu, H.L.; Méjean, G.; Kamali, Y.; Daigle, J.F.; Azarm, A.; Simard, P.T.; Mathieu, P.; Roy, G.; Chin, S.L. Efficient non-gated remote filament-induced breakdown spectroscopy of metallic sample. Spectrochim. Acta Part B 2007, 62, 76-81.

93. Xu, H.L.; Liu, W.; Chin, S.L. Remote time-resolved filament-induced breakdown spectroscopy of biological materials. Opt. Lett. 2006, 31, 1540-1542.

94. Rohwetter, Ph.; Stelmaszczyk, K.; Wöste, L.; Ackermann, R.; Méjean, G.; Salmon, E.; Kasparian, J.; Yu, J.; Wolf, J.P. Filament-induced remote surface ablation for long range laserinduced breakdown spectroscopy operation. Spectrochim. Acta Part B 2005, 60, 1025-1033.

95. Tzortzakis, S.; Anglos, D.; Gray, D. Ultraviolet laser filaments for remote laser-induced breakdown spectroscopy (LIBS) analysis: Applications in cultural heritage monitoring. Opt. Lett. 2006, 31, 1139-1141.

96. Mirell, D.; Chalus, O.; Peterson, K.; Diels, J.C. Remote sensing of explosives using infrared and ultraviolet filaments. J. Opt. Soc. Am. B 2008, 25, B108-B111. 
97. Judge, E.J.; Heck, G.; Cerkez, E.B.; Levis, R.J. Discrimination of Composite Graphite Samples Using Remote Filament-Induced Breakdown Spectroscopy. Anal. Chem. 2009, 81, 2658-2663.

98. Fujii, T.; Goto, N.; Miki, M.; Nayuki, T.; Nemoto, K. Lidar measurement of constituents of microparticles in air by laser-induced breakdown spectroscopy using femtosecond terawatt laser pulses. Opt. Lett. 2006, 31, 3456-3458.

99. Daigle, J.-F.; Mathieu, P.; Roy, G.; Simard, J.-R.; Chin, S.L. Multi-constituents detection in contaminated aerosol clouds using remote-filament-induced breakdown spectroscopy. Opt. Commun. 2007, 278, 147-152.

100. Méjean, G.; Kasparian, J.; Yu, J.; Frey, S., Salmon, E.; Wolf, J.-P. Remote detection and identification of biological aerosols using a femtosecond terawatt lidar system. Appl. Phys. B 2004, 78, 535-537.

101. Hill, S.C.; Boutou, V.; Yu, J.; Ramstein, S.; Wolf, J.-P.; Pan, Y.-L.; Holler, S.; Chang, R.K. Enhanced backward-directed multiphoton-excited fluorescence from dielectric microcavities. Phys. Rev. Lett. 2000, 85, 54-57.

102. Favre, C.; Boutou, V.; Hill, S.C.; Zimmer, W.; Krenz, M.; Lambrecht, H.; Yu, J.; Chang, R.K.; Woeste, L.; Wolf, J.-P. White-light nanosouce with directional emission. Phys. Rev. Lett. 2002, 89, $035002(1-4)$.

103. Luo, Q.; Liu, W.; Chin, S.L. Lasing action in air induced by ultrafast laser filamentation. Appl. Phys.B 2003, 76, 337-340.

104. Song, D.; Azarm, A.; Kamali, Y.; Liu, K.; Xia, A.; Teranishi, Y.; Lin, S.; Kong, F.; Chin, S.L. Neutral dissociation of superexcited oxygen molecules in intense laser fields. J. Phys. Chem. A 2010, 114, 3087-3095.

105. Liu, K.; Song, D.; Azarm, A.; Chin, S.L.; Kong, F. Neutral dissociation of superexcited nitric oxide induced by intense laser fields. Chin. J. Chem. Phys. 2010, 23, 252-354.

106. Kasparian, J.; Brämer, B.; Dewitz, J.P.; Vajda, S.; Rairoux, P.; Vezin, B.; Boutou, V.; Leisner, T.; Hübner, W.; Wolf, J.-P.; Wöste, L.; Bennemann, K.H. Angular dependences of third harmonic generation from microdroplets. Phys. Rev. Lett. 1997, 78, 2952-2955.

107. Boutou, V.; Favre, C.; Woeste, L.; Wolf, J.-P. Measuring the electric charge in cloud droplets by use of second-harmonic generation. Opt. Lett. 2005, 78, 759-761.

108. Théberge, F.; Luo, Q.; Liu, W.; Hosseini, S.A.; Sharifi, S.M.; Chin, S.L. Long-range third-harmonic generation in air using ultrashort intense laser pulses. Appl. Phys. Lett. 2005, 87, $081108(1-3)$.

109. Kasparian, J.; Sauerbrey, R.; Mondelain, D.; Niedermeier, S.; Yu, J.; Wolf, J.-P.; André, Y.-B.; Franco, M.; Prade, B.; Tzortzakis, S.; Mysyrowicz, A.; Rodriguez, M.; Wille, H.; Wöste, L. Infrared extension of the supercontinuum generated by femtosecond terawatt laser pulses propagating in the atmosphere. Opt. Lett. 2000, 25, 1397-1399.

110. Somekawa, T.; Yamanaka, C.; Fujita, M.; Galvez, M.C. Simultaneous three-wavelength depolarization measurements of clouds and aerosols using a coherent white light continuum. J. Appl. Phys. 2008, 103, 043101(1-5).

111. Tera Mobile. Available online: http://www.teramobile.org/ (accessed on 21 December 2010). 
112. Rairoux, P.; Schillinger, H.; Niedermeier, S.; Rodriguez, M.; Ronneberger, F.; Sauerbrey, R.; Stein, B.; Waite, D.; Wedekind, C.; Wille, H.; Wöste, L.; Ziener, C. Remote sensing of the atmosphere using ultrashort laser pulses. Appl. Phys. B 2000, 6, 573-580.

113. Méjean, G.; Kasparian, J.; Rodriguez, M.; Salmon, E.; Yu, J.; Lehmann, H.; Stecklum, B.; Laux, U.; Eislöffel, J.; Scholz, A.; Hatzes, A.P.; Sauerbrey, R.; Wöste, L. White-light filaments for multiparameter analysis of cloud microphysics. J. Opt. Soc. Am. B 2005, 22, 369-377.

114. Méjean, G. Propagation d'impulsions femtosecondes térawatts dans l'atmosphère et applications. Annales de physique 2005, 30, 1-154.

115. Somekawa, T.; Fujita, M.; Izawa, Y. Direct absorption spectroscopy of $\mathrm{CO}_{2}$ using a coherent white light continuum. Appl. Phys. Exp. 2010, 3, 082401(1-3).

116. Galvez, M.C.; Fujita, M.F.; Inoue, N.; Moriki, R.; Izawa, Y.; Yamanaka, C. Three-wavelength backscatter measurement of clouds and aerosols using a white light Lidar system. Jpn. J. Appl. Phys. 2002, 41, L284-L286.

117. Somekawa, T.; Yamanaka, C.; Fujita, M.; Galvez, M.C. Depolarization light detection and ranging using a white light LIDAR system. Jpn. J. Appl. Phys. 2006, 45, L165-L168.

118. Somekawa, T.; Yamanaka, C.; Fujita, M.; Galvez, M.C. Observation of Asian dust aerosols with depolarization Lidar using a coherent white light continuum. Jpn. J. Appl. Phys. 2008, 47, 2155-2157.

(C) 2010 by the authors; licensee MDPI, Basel, Switzerland. This article is an open access article distributed under the terms and conditions of the Creative Commons Attribution license (http://creativecommons.org/licenses/by/3.0/). 